\title{
The timing of the evening meal: how is this associated with weight status in UK children?
}

\author{
Janine D. Coulthard ${ }^{1}$ and Gerda K. Pot $^{1,2 *}$ \\ ${ }^{1}$ Faculty of Life Sciences and Medicine, Diabetes and Nutritional Sciences Division, King's College London, Franklin-Wilkins \\ Building, 150 Stamford Street, SE1 9NH, London, UK \\ ${ }^{2}$ Faculty of Earth and Life Sciences, Section of Health and Life, Vrije University Amsterdam, de Boelelaan 1085 , 1081 HV \\ Amsterdam, The Netherlands
}

(Submitted 22 September 2015 - Final revision received 28 January 2016 - Accepted 30 January 2016 - First published online 15 March 2016$)$

\section{Abstract}

There is some evidence from studies in adults and limited evidence from studies in children that eating later in the day may increase the risk of overweight and obesity. In this cross-sectional study, we investigated associations between evening meal timing in children and their weight status and energy intake. Dietary data obtained from the UK's National Diet and Nutrition Survey Rolling Programme (2008-2012) for 768 children aged 4-10 years and 852 children aged 11-18 years were analysed. We tested for an association between evening meal timing (consuming the evening meal before or after 20.00 hours) and risk of overweight and/or obesity, adjusting for relevant confounding variables. We also explored whether evening meal timing was associated with overall nutrient intake. We found no association between evening meal timing and risk of obesity or risk of overweight and obesity combined in either the 4-10 years age group (obesity: OR 1.43; $95 \%$ CI 0.49, 4.13; obesity and overweight combined: OR $1.33 ; 95 \% \mathrm{CI} 0 \cdot 53,3 \cdot 33$ ) or the $11-18$ years age group (obesity: OR 0.50; $95 \% \mathrm{CI} 0 \cdot 24,1 \cdot 02$; obesity and overweight combined: OR 0.83; $95 \% \mathrm{CI}$ $0 \cdot 50,1.38)$, split by sex or as combined. No significant associations were found between evening meal timing and energy intake, and no clear patterns in variation of nutrient intakes with evening meal times were identified. In conclusion, we found no evidence that, for children aged 4-18 years in the UK, eating the evening meal after 20.00 hours was associated with excess weight or increased energy intake.

Key words: Children's dietary patterns: Meal timings: National Diet and Nutrition Survey Rolling Programme: Childhood obesity

Childhood obesity is a major public health issue in the UK. At present, interventions targeting child obesity are aimed at improving dietary quality and increasing energy expenditure ${ }^{(1)}$. However, results of animal and human studies on the influence of circadian rhythms - the body's internal, daily, cyclical clock - on metabolic processes suggest that the timing of food intake may also play an important role in body weight regulation ${ }^{(2,3)}$. If it can be demonstrated that meal timing influences the weight status of children, the alteration of meal times could be a useful additional public health strategy in tackling the high levels of overweight and obesity currently prevalent in children in the UK.

Circadian rhythms are governed by a 'master' clock in the suprachiasmatic nucleus ( $\mathrm{SCN}$ ) of the hypothalamus, which is synchronised to the external light-dark cycle. Peripheral clocks, synchronised to the master SCN clock, are found in other parts of the body, such as the pancreas, liver and adipose tissue. The master and peripheral clocks together regulate the expression and activity of metabolic hormones and enzymes, including those involved in energy metabolism ${ }^{(3,4)}$. Feeding schedule may act as an external synchroniser of the peripheral clocks, over-riding the SCN rhythm, so that the peripheral clocks become desynchronised (or uncoupled) from the master clock. This chrono-disruption has been hypothesised to lead to the adverse health effects associated with unusual feeding times ${ }^{(3,5-8)}$.

There is evidence from animal studies linking disruption of the circadian clock through alteration of the clock time of meals with obesity and metabolic disorders ${ }^{(8)}$. Studies in human adults on non-breakfast eaters ${ }^{(9)}$, shift workers ${ }^{(10)}$ and night-eating syndrome patients $^{(11)}$ also support a link between eating at times outside the 'normal' circadian pattern and weight gain. Results from several observational studies suggest that adults consuming a greater proportion of their daily energy intake or meals in the evening are more likely to be overweight or obese $\mathrm{e}^{(12-14)}$. To the best of our knowledge, there are very few studies that have examined the impact of meal timing on the weight status of children. A longitudinal study of 101 girls (aged 8-12 years at baseline) found that mean energy intake on weekday evenings was positively associated $(P=0.039)$ with change in BMI 2-10 years later. However, no significant associations were found between change in BMI and mean

Abbreviations: DRV, dietary reference values; EAR, estimated average requirement; NDNS RP, National Diet and Nutrition Survey Rolling Programme. 
energy intakes on weekend evenings or weekday and weekend evenings combined ${ }^{(15)}$. A cross-sectional analysis of US National Health and Nutrition Examination Survey data for 2-18-year-olds ( $n$ 11072) indicated that increased energy intake in the time period 18.00 to 19.59 hours compared with 16.00 to 17.59 hours was positively associated with overweight in 6-11-year-olds, but was negatively associated with overweight in 12-18-year-olds ${ }^{(16)}$. In addition, a significantly greater proportion of daily energy was consumed by overweight and obese children compared with healthy weight children between 16.00 hours and midnight, but not between 20.00 hours and midnight.

There is some evidence from adult studies that food consumption patterns may influence energy intake. A cross-sectional study in the US based on 7-d food diaries ( $n$ 867) found that the proportion of energy consumed in the morning was negatively correlated and the proportion consumed in the later evening was positively correlated with total energy intake, possibly due to weaker satiety mechanisms at night ${ }^{(17)}$. It has been suggested that meal timing may be a proxy for specific patterns of nutrient intake $^{(14,18)}$; however, there is little evidence for this in adults ${ }^{(12,14)}$ or children ${ }^{(19)}$. Therefore, we aimed to investigate the potential link between children's evening meal time and their weight status, daily energy intake and dietary quality. We hypothesised that children with a later evening meal time would have a greater risk of being overweight and/or obese, have higher daily intakes of energy and have poorer quality of diet.

\section{Methods \\ Population}

This study used data collected between 2008 and 2012 as part of the UK's National Diet and Nutrition Survey Rolling Programme (NDNS RP) ${ }^{(20)}$. The NDNS RP is a cross-sectional study of the dietary habits and nutritional status of individuals in the UK. Its aim is to collect dietary and nutritional data from a UK representative sample of 1000 people/year, comprising equal numbers of adults (aged 19 years and over) and children (aged 1.5-18 years) living in private households ${ }^{(21)}$. Ethics approval for the NDNS RP was obtained from Oxfordshire A Research Ethics Committee ${ }^{(21)}$. Further details of the methodology of the NDNS RP are given in chapter 2 of the report on the NDNS results from years 1-4 (combined) of the rolling programme ${ }^{(21)}$. In brief, the NDNS RP sample was selected using addresses randomly taken from The Royal Mail's Postcode Address File, which comprises all UK $\operatorname{addresses}^{(22)}$. If there were several households at the same address, one household was randomly selected ${ }^{(22)}$. At some households one adult and one child (if present) were selected and at others only a child was selected to give a 'child boost', so as to obtain roughly equal numbers of children and adults ${ }^{(22)}$. Extra addresses were selected in Wales, Scotland and Northern Ireland for a 'country boost', but these were not included in the archived NDNS RP 'core sample' data set used in this study. Survey interviewers visited the home of each participant and carried out a face-to-face computer-assisted personal interview with the survey participant (or their parent or guardian, for children under 8 years $)^{(23)}$. The interviewer measured the weight and height of the participant so that their BMI could be calculated ${ }^{(21)}$. The BMI measurements for participants aged 4-18 years were compared with British 1990 growth reference (UK90) charts $^{(24)}$ to assess whether children were normal weight, overweight (85th centile cut-off) or obese (95th centile cut-off) ${ }^{(21)}$.

\section{Dietary assessment}

A 4-d estimated (unweighed) food diary was left with each participant, to be completed for a specified period of 4 consecutive diary days, and was collected no later than $3 \mathrm{~d}$ after the final diary day ${ }^{(21)}$. A parent was asked to complete the food diary for those participants aged 11 years and under (with the child's help, if appropriate) ${ }^{(25)}$. The core sample for years 2008-2012 of the NDNS RP (NDNS 2008-12 RP) included 1687 children aged 4-18 years who had completed at least three diary days $(98.2 \%$ completed four diary days). BMI data were not obtained or were invalid for sixty-seven of these 1687 children. Therefore, the final sample included in this study was 1620 children.

Food composition data from the Department of Health's NDNS Nutrient Databank were used to estimate nutrient intakes based on the diary entries ${ }^{(25)}$. This incorporates information from McCance and Widdowson's The Composition of Foods series ${ }^{(25,26)}$. For participants aged 11 years and older, a portion weight of $80 \mathrm{~g}$ ( $150 \mathrm{~g}$ for fruit juice) was used to calculate portions of fruits and vegetables consumed, based on the Department of Health's '5-a-day' recommendation ${ }^{(25,27)}$. Dietary fibre intakes were expressed as intakes of NSP, defined by the Englyst method ${ }^{(28)}$. Intakes of non-milk extrinsic sugars (NMES) included all free sugars (added monosaccharides and disaccharides, and naturally occurring sugars in honey, syrups and fruit juices) plus $50 \%$ of fruit sugars from stewed, dried or canned fruit ${ }^{(29)}$.

The food diary included columns to indicate the exact time (e.g. 07.00 hours) and also the time period (e.g. 06.00 to 09.00 hours) in which the food was eaten (the diary was pre-structured into seven different time periods) ${ }^{(23)}$. In the NDNS RP data set used in this study, the energy value for the food eaten was linked to the time period in which it was eaten. Microsoft Excel for Mac 2011 (version 14.4.7) and IBM SPSS Statistics (version 22) were used to transform these energy intake data into totals for each of the relevant time periods: 14.00 to 16.49 hours, 17.00 to 19.59 hours and 20.00 to 21.59 hours. The time period between 14.00 and 21.59 hours with the highest total energy intake for a child was designated the evening meal time period for that child. We hypothesised that consuming the evening meal in the latest time period (after 20.00 hours), that is, unusually late, compared with one of the earlier two time periods (before 20.00 hours), might have adverse metabolic consequences, and thus be associated with a higher prevalence of overweight and obesity ${ }^{(3)}$.

The nutrient intakes chosen for analysis in this study were intakes of the macronutrients carbohydrates, fats and proteins, together with intakes of specific nutrients and foods associated with unhealthy (SFA, trans-fatty acids (TFA), NMES) or healthy (NSP and fruit and vegetable portions) dietary patterns, based on UK government recommendations ${ }^{(30,31)}$. Data were compared with dietary reference values (DRV) and dietary recommendations, as specified by the Committee on Medical 
Aspects of Food Policy (COMA) ${ }^{(32)}$ and the Scientific Advisory Committee on Nutrition $(\mathrm{SACN})^{(29)}$. SACN's recently revised DRV for dietary fibre, which are based on the AOAC International methods, range from $15-20 \mathrm{~g}$ for 4-10-year-olds and 25-30 g for 11-18-year-olds. These approximate to 11-15 and 19-23 g, respectively, by the Englyst method. SACN's recent recommendation is that a maximum of $5 \%$ of total dietary energy should derive from free sugars ${ }^{(29)}$.

\section{Statistical analysis}

Dietary variables are presented as mean values and standard deviations. Where needed, non-normally distributed data were transformed. The Kolmogorov-Smirnov and the Shapiro-Wilk normality tests were applied, followed by inspection of frequency distribution histograms for variables that failed one or both of these tests. Data were split by sex and age group (4-10 years and 11-18 years) to allow for variations in eating habits between the sexes and the shift to later evening meal times when children transition from primary to secondary school. $\chi^{2}$ Analysis was carried out on weight status and evening meal time data. Logistic regression models were used to calculate the risk of overweight/obesity and obesity compared with normal weight for consuming the evening meal after 20.00 hours compared with before 20.00 hours. Our models were run adjusting for household income (equivalised to take account of differences in size and composition of households ${ }^{(21)}$ ), ethnicity and, where appropriate, sex. Unpaired $t$ tests were carried out to test for an association between the dietary variables and eating the evening meal before or after 20.00 hours. Equal variances were assumed for all unpaired $t$ tests. All the dietary variables selected for the $t$ tests, except for the number of portions of fruits and vegetables consumed, were expressed either as a percentage of DRV or total food energy, to allow for differences in age and sex. For the $t$ tests, a $P$ value of $<0.01$ was considered as statistically significant to allow for multiple testing ${ }^{(33)}$. For all other analyses, a $P$ value of $<0.05$ was used to determine significance. We did not apply the weighting as provided with the NDNS 2008-12 RP data set ${ }^{(34)}$, as it resulted in a reduction of more than $50 \%$ in the sample numbers, in part due to correction for the child boost applied in sample selection. As a result, the sample as analysed in this study may not be representative of the UK population.

\section{Results \\ Description of population}

The characteristics of the children, split by age and sex, are set out in Table 1 . Overall obesity rates were higher in the 11-18 years age group than in the 4-10 years age group (21 $v$. $16 \%, P=0.007)$, as were combined rates of overweight and obesity ( $35 v .29 \%, P=0.005)$. There was a higher proportion of obese and overweight/obese girls than boys overall and in each age category, but the difference was not statistically significant. The majority of children ( $83 \%$ of children aged $4-10$ years and $75 \%$ of children aged 11-18 years) consumed their evening meal between 17.00 and 19.59 hours. At 9\%, the proportion of girls generally taking their evening meal between 20.00 and 21.59 hours was higher than the proportion of boys, which was $6 \%(P=0.029)$.

For children aged 4-10 years, total mean energy intakes were $96 \%$ of the estimated average requirement (EAR) (as set by COMA $^{(32)}$ ) and for $11-18$-year-old children they were $75 \%$ of the EAR. Mean daily intakes of NMES as a percentage of food energy were 14.7 and $14.6 \%$ for 4-10-year-old boys and girls, respectively, and 16.0 and $15.2 \%$ for $11-18$-year-old boys and girls. Mean fibre intakes were at the bottom end of the range of DRV for the 4-10 years age group - 11.1 (SD 3.2) g - and were well below the DRV for 11-18-year-olds - 11.8 (sD 4.1) g. At an average of 2.9 (SD 1.6) portions/d, fruit and vegetable intakes for 11-18-year-olds (data not gathered for 4-10-year-olds) fell well short of the UK government's '5-a-day' recommendation. Although mean SFA intakes as a percentage of food energy were above the $11 \%$ recommended maximum population average ( 13.2 and $12.5 \%$ for the $4-10$ years and $11-18$ years age groups, respectively), mean TFA intakes were below the recommended upper limit of $2 \%$ ( $0.6 \%$ for both the $4-10$ years and the 11-18 years age groups).

\section{Meal timing and risk of overweight and obesity}

Boys and girls aged 4-10 years, separately or combined, had no higher risk of being obese when eating the evening meal between 20.00 and 21.59 hours compared with eating the evening meal between 14.00 and 19.59 hours (Table 2). Similarly, there was no variation in risk for obesity for 11-18-year-olds as a group or when stratified by sex. There was also no association of risk of overweight and obesity combined with evening meal time in boys and/or girls in either age group.

\section{Meal timing and nutrient intakes}

There were no significant differences in mean daily energy intakes (as a percentage of EAR) of the children, split by age and sex, for those eating their evening meal before 20.00 hours compared with those eating their evening meal after 20.00 hours (Table 3 ). There was a small number of statistically significant differences in mean daily nutrient intakes when comparing intakes of those children who ate their evening meal before 20.00 hours with those eating later. Daily protein intakes as a percentage of food energy were significantly higher for 4-10-year-old boys $(P=0.002)$, with a mean of 14.5 (SD 2.3)\% consumed by those eating their evening meal between 14.00 and 19.59 hours compared with a mean of 17.4 (SD 4.9 ) \% consumed by those eating their evening meal between 20.00 and 21.59 hours. For 11-18-year-old girls, there was a significant difference in mean daily carbohydrate intakes as a percentage of food energy $(P=0.006)$, with a lower mean percentage intake ( $49.0 \mathrm{v} .51 .3 \%)$ for those girls eating their evening meal between 20.00 and 21.59 hours compared with those eating their meal between 14.00 and 19.59 hours. A similar trend in carbohydrate intakes was observed for the 11-18-year-olds as a group $(P=0.003)$. 
Table 1. Characteristics of children, split by age group and sex, showing weight status, evening meal time period and values for daily dietary intakes of energy, nutrients and fruit and vegetable ('5-a-day') portions

(Numbers and percentages; mean values and standard deviations)

\begin{tabular}{|c|c|c|c|c|c|c|c|c|c|c|c|c|}
\hline & \multicolumn{6}{|c|}{$4-10$ years } & \multicolumn{6}{|c|}{$11-18$ years } \\
\hline & \multicolumn{2}{|c|}{ Boys ( $n$ 396) } & \multicolumn{2}{|c|}{ Girls ( $n$ 372) } & \multicolumn{2}{|c|}{ All $(n 768)$} & \multicolumn{2}{|c|}{ Boys ( $n$ 427) } & \multicolumn{2}{|c|}{ Girls ( $n$ 425) } & \multicolumn{2}{|c|}{ All $(n$ 852) } \\
\hline & $n$ & $\%$ & $n$ & $\%$ & $n$ & $\%$ & $n$ & $\%$ & $n$ & $\%$ & $n$ & $\%$ \\
\hline \multicolumn{13}{|l|}{ Weight status } \\
\hline Normal weight & 285 & 71.9 & 264 & 71.0 & 549 & 71.5 & 288 & 67.4 & 265 & $62 \cdot 3$ & 553 & 64.9 \\
\hline Overweight & 51 & $12 \cdot 8$ & 46 & 12.4 & 97 & $12 \cdot 6$ & 62 & 14.5 & 62 & 14.6 & 124 & 14.6 \\
\hline Obese & 60 & $15 \cdot 2$ & 62 & $16 \cdot 7$ & 122 & 15.9 & 77 & 18.0 & 98 & 23.0 & 175 & 20.5 \\
\hline \multicolumn{13}{|l|}{ Evening meal time period } \\
\hline 14.00 to 16.59 hours & 44 & $11 \cdot 1$ & 59 & $15 \cdot 9$ & 103 & 13.4 & 59 & $13 \cdot 8$ & 63 & $14 \cdot 8$ & 122 & $14 \cdot 3$ \\
\hline 17.00 to 19.59 hours & 343 & $86 \cdot 6$ & 297 & 79.8 & 640 & $83 \cdot 3$ & 328 & $76 \cdot 8$ & 308 & 72.5 & 636 & 74.6 \\
\hline \multirow[t]{2}{*}{20.00 to 21.59 hours } & 9 & $2 \cdot 3$ & 16 & 4.3 & 25 & 3.3 & 40 & 9.4 & 54 & $12 \cdot 7$ & 94 & 11.0 \\
\hline & Mean & SD & Mean & SD & Mean & SD & Mean & SD & Mean & SD & Mean & SD \\
\hline $\mathrm{TE}(\mathrm{MJ} / \mathrm{d})$ & $6 \cdot 6$ & 1.4 & $6 \cdot 2$ & 1.4 & $6 \cdot 4$ & 1.4 & 8.3 & $2 \cdot 3$ & $6 \cdot 7$ & $1 \cdot 7$ & 7.5 & $2 \cdot 2$ \\
\hline $\mathrm{TE}(\mathrm{kcal} / \mathrm{d})$ & 1563 & 322 & 1483 & 323 & 1524 & 325 & 1982 & 537 & 1584 & 414 & 1783 & 519 \\
\hline $\mathrm{FE}(\mathrm{MJ} / \mathrm{d})$ & 6.6 & 1.4 & $6 \cdot 2$ & 1.4 & 6.4 & 1.4 & $8 \cdot 3$ & $2 \cdot 2$ & 6.6 & 1.7 & 7.4 & $2 \cdot 1$ \\
\hline $\mathrm{FE}(\mathrm{kcal} / \mathrm{d})$ & 1563 & 322 & 1483 & 323 & 1524 & 325 & 1964 & 524 & 1572 & 407 & 1768 & 508 \\
\hline TE (\% EAR) & 95.0 & 18.9 & $96 \cdot 6$ & 21.4 & 95.8 & 20.2 & 75.6 & $20 \cdot 8$ & $69 \cdot 1$ & 18.5 & 72.4 & 19.9 \\
\hline Protein $(\mathrm{g} / \mathrm{d})$ & $56 \cdot 7$ & 13.6 & $52 \cdot 9$ & $12 \cdot 9$ & 54.9 & 13.4 & 74.3 & 23.0 & $57 \cdot 1$ & $15 \cdot 7$ & $65 \cdot 8$ & 21.5 \\
\hline Protein $(\% \mathrm{FE})^{*}$ & 14.6 & 2.4 & $14 \cdot 3$ & $2 \cdot 2$ & 14.5 & $2 \cdot 3$ & $15 \cdot 3$ & 3.1 & $14 \cdot 8$ & $3 \cdot 1$ & $15 \cdot 0$ & 3.1 \\
\hline Protein (\% RNI) & 235 & 56 & 222 & 63 & 229 & 60 & 155 & 48 & 133 & 37 & 144 & 44 \\
\hline Fat $(\mathrm{g} / \mathrm{d})$ & 58.0 & $15 \cdot 4$ & $56 \cdot 1$ & $16 \cdot 5$ & $57 \cdot 1$ & $16 \cdot 0$ & $74 \cdot 3$ & 23.9 & $60 \cdot 4$ & 19.9 & $67 \cdot 4$ & 23.0 \\
\hline Fat $(\% \mathrm{FE})^{*}$ & 33.3 & 4.6 & 33.7 & 4.6 & 33.5 & 4.6 & 33.8 & 4.6 & 34.2 & $5 \cdot 2$ & 34.0 & 4.9 \\
\hline SFA $(g / d)$ & 22.9 & $7 \cdot 2$ & $22 \cdot 1$ & $7 \cdot 4$ & 22.5 & $7 \cdot 3$ & 28.0 & $10 \cdot 1$ & $22 \cdot 0$ & 8.3 & $25 \cdot 0$ & 9.7 \\
\hline SFA (\% FE) $)^{*}$ & $13 \cdot 1$ & 2.7 & $13 \cdot 3$ & $2 \cdot 7$ & 13.2 & 2.7 & $12 \cdot 7$ & 2.5 & $12 \cdot 4$ & 2.7 & 12.5 & 2.6 \\
\hline TFA $(\mathrm{g} / \mathrm{d})$ & $\begin{array}{r}1.1 \\
1.1\end{array}$ & 0.5 & 1.1 & 0.5 & 1.1 & 0.5 & 1.4 & 0.7 & 1.1 & 0.6 & $1 \cdot 2$ & 0.6 \\
\hline TFA (\% FE)* & 0.6 & 0.3 & 0.6 & 0.2 & 0.6 & 0.2 & 0.6 & 0.2 & 0.6 & 0.3 & 0.6 & 0.3 \\
\hline $\mathrm{CHO}(\mathrm{g} / \mathrm{d})$ & 217 & 48 & 204 & 44 & 211 & 46 & 266 & 75 & 213 & 59 & 240 & 72 \\
\hline $\mathrm{CHO}(\% \mathrm{FE})^{*}$ & $52 \cdot 2$ & 4.9 & 51.9 & 4.8 & $52 \cdot 1$ & 4.9 & 50.9 & 5.4 & 51.0 & $5 \cdot 7$ & 50.9 & 5.6 \\
\hline NMES $(\mathrm{g} / \mathrm{d})$ & $62 \cdot 3$ & 29.3 & 58.4 & 24.4 & 60.4 & 27.1 & 85.2 & 44.0 & $65 \cdot 1$ & 35.2 & 75.2 & 41.1 \\
\hline NMES (\% FE) $†$ & 14.7 & $5 \cdot 6$ & $14 \cdot 6$ & 4.9 & 14.7 & $5 \cdot 3$ & $16 \cdot 0$ & $6 \cdot 6$ & $15 \cdot 2$ & $6 \cdot \overline{6}$ & $15 \cdot \overline{6}$ & 6.6 \\
\hline $\operatorname{NSP}(\mathrm{g} / \mathrm{d}) \ddagger$ & 11.4 & 3.2 & 10.7 & $3 \cdot 1$ & 11.1 & 3.2 & $12 \cdot 8$ & 4.4 & $10 \cdot 8$ & 3.5 & 11.8 & 4.1 \\
\hline 5-a-day (portions/d)§ & - & - & - & - & - & - & 3.0 & 1.6 & $2 \cdot 8$ & 1.6 & 2.9 & 1.6 \\
\hline
\end{tabular}

TE, total energy (includes energy from alcohol); FE, food energy; EAR, estimated average requirement (as set by the Committee on Medical Aspects of Food Policy (COMA)); RNI, reference nutrient intake (as set by COMA); TFA, trans-fatty acids; $\mathrm{CHO}$, carbohydrate; NMES, non-milk extrinsic sugars; NSP by the Englyst method; 5-a-day fruit and vegetable '5-a-day' portions.

* Dietary recommendations (average population intakes) as set by $\mathrm{COMA}^{(32)}$ for nutrients as a percentage of daily $\mathrm{FE}$ intake are as follows: $35 \%$ for fat, $50 \%$ for $\mathrm{CHO}$ and $15 \%$ for protein, and no more than $11 \%$ for SFA and $2 \%$ for TFA.

$\dagger$ The revised dietary recommendation for average population intake of free sugars set by the Scientific Advisory Committee on Nutrition (SACN) ${ }^{(29)}$ is no more than $5 \%$ of TE. NMES are free sugars plus $50 \%$ of fruit sugars from stewed, dried or canned fruit.

$\ddagger$ Revised SACN dietary reference value for dietary fibre intake based on the AOAC International methods range from 15-20 g for 4-10-year-olds and 25-30 g for 11-18-year-olds,

which approximates to $11-15$ and $19-23 \mathrm{~g}$, respectively, of NSP by the Englyst method ${ }^{(28)}$.

$\S$ Data on fruit and vegetable '5-a-day' portions only available for the 11-18 years age group.

Table 2. Risk of overweight/obesity $v$. normal weight and obesity $v$. normal weight for children consuming their evening meal between 20.00 and 21.59 hours compared with those consuming their evening meal between 14.00 and 19.59 hours, split by age group and sex*

(Odds ratios (OR) and $95 \%$ confidence intervals)

\begin{tabular}{|c|c|c|c|c|c|c|c|c|c|c|c|c|}
\hline & \multicolumn{6}{|c|}{$4-10$ years } & \multicolumn{6}{|c|}{$11-18$ years } \\
\hline & \multicolumn{2}{|c|}{ Boys ( $n$ 396) } & \multicolumn{2}{|c|}{ Girls (n 372) } & \multicolumn{2}{|c|}{ All $(n 768)$} & \multicolumn{2}{|c|}{ Boys ( $n$ 427) } & \multicolumn{2}{|c|}{ Girls ( $n$ 425) } & \multicolumn{2}{|c|}{ All $(n$ 852) } \\
\hline & OR & $95 \% \mathrm{Cl}$ & OR & $95 \% \mathrm{Cl}$ & OR & $95 \% \mathrm{Cl}$ & OR & $95 \% \mathrm{Cl}$ & OR & $95 \% \mathrm{Cl}$ & OR & $95 \% \mathrm{Cl}$ \\
\hline Overw & 1.64 & $0.37,7.26$ & 1.11 & $0.34,3.59$ & 1.33 & $0.53,3.33$ & 1.02 & $0.48,2 \cdot 18$ & 0.71 & $0.35,1.42$ & 0.83 & $0.50,1.38$ \\
\hline Obesity ( $>95$ th centile) $\dagger$ & 1.97 & $0.37,10.62$ & 1.26 & $0.32,5.01$ & 1.43 & $0.49,4.13$ & 0.43 & $0.13,1.45$ & 0.56 & $0.22,1.39$ & 0.50 & $0.24,1.02$ \\
\hline
\end{tabular}

* Results shown are adjusted for equivalised household income, ethnicity and, where appropriate, sex.

$\dagger$ The BMI measurements for the children were compared with British 1990 growth reference (UK90) ${ }^{(24)}$ charts to assess whether children were normal weight, overweight (85th centile cut-off) or obese (95th centile cut-off).

\section{Discussion}

In contrast to several previous adult studies $^{(12-14)}$ and some limited evidence from studies including children ${ }^{(15,16)}$, in this cross-sectional study, after adjusting for confounding variables, we found no higher risk of obesity or overweight and obesity among those children consuming their evening meal after 20.00 hours. Furthermore, we found no significant differences 
Table 3. Results of unpaired $t$ tests comparing dietary intakes for (a) children aged 4-10 years and (b) children aged 11-18 years, whose evening meal is consumed between 14.00 and 19.59 hours (early) with those whose evening meal is consumed between 20.00 and 21.59 hours (late)

(Mean values and standard deviations)

\begin{tabular}{|c|c|c|c|c|c|c|c|c|c|c|c|c|c|c|c|}
\hline & \multicolumn{5}{|c|}{ Boys ( $n$ 396) } & \multicolumn{5}{|c|}{ Girls ( $n$ 372) } & \multicolumn{5}{|c|}{ All $(n 768)$} \\
\hline & \multicolumn{2}{|c|}{ Early ( $n$ 387) } & \multicolumn{2}{|c|}{ Late $(n 9)$} & \multirow[b]{2}{*}{$P$} & \multicolumn{2}{|c|}{ Early ( $n$ 356) } & \multicolumn{2}{|c|}{ Late $(n 16)$} & \multirow[b]{2}{*}{$P$} & \multicolumn{2}{|c|}{ Early ( $n 743)$} & \multicolumn{2}{|c|}{ Late $(n$ 25) } & \multirow[b]{2}{*}{$P$} \\
\hline & Mean & SD & Mean & SD & & Mean & SD & Mean & SD & & Mean & SD & Mean & SD & \\
\hline \multicolumn{16}{|c|}{ (a) Children aged 4-10 years } \\
\hline TE (\% EAR) & $95 \cdot 3$ & $18 \cdot 8$ & $80 \cdot 8$ & $17 \cdot 5$ & 0.023 & $96 \cdot 2$ & $20 \cdot 8$ & $107 \cdot 4$ & $31 \cdot 4$ & 0.040 & $95 \cdot 7$ & $19 \cdot 8$ & $97 \cdot 8$ & $29 \cdot 8$ & 0.610 \\
\hline Protein $(\% \text { FE) })^{\star}$ & 14.5 & $2 \cdot 3$ & $17 \cdot 4$ & 4.9 & 0.002 & $14 \cdot 4$ & 2.2 & $13 \cdot 7$ & 2.5 & 0.174 & 14.5 & $2 \cdot 2$ & $15 \cdot 0$ & 3.9 & 0.494 \\
\hline Protein $(\% \mathrm{RNI}) \dagger$ & 235 & 57 & 222 & 44 & 0.539 & 222 & 62 & 236 & 81 & 0.480 & 229 & 60 & 231 & 69 & 0.943 \\
\hline Fat (\% FE) & 33.3 & 4.6 & 32.2 & 5.0 & 0.475 & 33.7 & 4.6 & 34.3 & 6.4 & 0.603 & 33.5 & 4.6 & 33.5 & 5.9 & 0.947 \\
\hline SFA (\% FE)† & 13.2 & $2 \cdot 7$ & 11.9 & $2 \cdot 8$ & 0.160 & $13 \cdot 3$ & $2 \cdot 7$ & 12.5 & 3.5 & 0.190 & $13 \cdot 2$ & $2 \cdot 7$ & $12 \cdot 3$ & 3.2 & 0.063 \\
\hline TFA $(\%$ FE $) \dagger$ & 0.62 & 0.23 & 0.57 & 0.28 & 0.386 & 0.63 & 0.24 & 0.54 & 0.24 & 0.120 & 0.63 & 0.24 & 0.55 & 0.25 & 0.080 \\
\hline $\mathrm{CHO}(\% \mathrm{FE})$ & $52 \cdot 2$ & 4.9 & $50 \cdot 4$ & $4 \cdot 1$ & 0.283 & 51.9 & 4.7 & $52 \cdot 1$ & 6.6 & 0.919 & $52 \cdot 1$ & 4.8 & 51.5 & $5 \cdot 8$ & 0.541 \\
\hline NMES $(\%$ FE) $†$ & $14 \cdot 8$ & $5 \cdot 6$ & 11.9 & 4.6 & 0.126 & 14.5 & 4.8 & 15.5 & $6 \cdot 6$ & 0.582 & 14.7 & $5 \cdot 2$ & 14.2 & $6 \cdot 1$ & 0.562 \\
\hline NSP $(g / d) \dagger$ & 11.4 & $3 \cdot 2$ & $10 \cdot 4$ & 3.3 & 0.328 & $10 \cdot 6$ & 3.0 & 11.4 & 4.3 & 0.442 & $11 \cdot 1$ & $3 \cdot 1$ & $11 \cdot 1$ & 3.9 & 0.863 \\
\hline 5-a-day (portions/d)†‡ & - & - & - & - & - & - & - & - & - & - & - & - & - & - & - \\
\hline
\end{tabular}

Boys $(n$ 427)

$\frac{\text { Early }(n \text { 387) }}{\text { Mean }} \frac{\text { Late }(n 40)}{\text { SD }}$

Girls ( $n$ 425)

$\frac{\text { Early }(n \text { 371) }}{\text { Mean }} \frac{\text { Late }(n \text { 54) }}{\text { SD }} P$

All $(n$ 852)

$\frac{\text { Early }(n \text { 758) }}{\text { Mean }} \frac{\text { Late }(n \text { 94) }}{\text { SD }} P$

(b) Children aged $11-18$ years

TE $(\%$ EAR)

Protein $(\% \mathrm{FE})^{\star}$

Protein $(\% \mathrm{RNI}) \dagger$

Fat $(\% \mathrm{FE})$

SFA (\% FE) $\dagger$

TFA (\% FE) $\dagger$

$\mathrm{CHO}$ (\% FE)

NMES (\% FE)†

NSP $(\mathrm{g} / \mathrm{d}) \dagger$

5-a-day (portions/d) †‡

\begin{tabular}{|c|c|c|c|c|c|c|c|c|c|c|c|c|c|c|}
\hline 76.0 & 20.8 & 71.3 & 19.9 & 0.175 & 68.9 & 18.2 & 70.6 & 20.9 & 0.529 & 72.5 & 19.9 & 70.9 & 20.4 & 0.459 \\
\hline $15 \cdot 3$ & $3 \cdot 1$ & 15.5 & 3.0 & 0.621 & 14.7 & 2.9 & 15.4 & 8 & 10 & $15 \cdot 0$ & .0 & 15.4 & 3.5 & .255 \\
\hline 56 & 48 & 149 & 48 & 0.379 & 132 & 36 & 140 & 43 & 0.198 & 144 & 44 & 144 & 45 & 99 \\
\hline 33.7 & 4.6 & 34.7 & 4.6 & 0.207 & 34.0 & 4.9 & 35.6 & $6 \cdot 3$ & 0.032 & 33.9 & 4.8 & 35.2 & 5.6 & 11 \\
\hline $12 \cdot 7$ & 2.5 & $12 \cdot 7$ & $2 \cdot 7$ & 0.957 & $12 \cdot 4$ & $2 \cdot 6$ & $12 \cdot 4$ & 3.0 & 0.941 & 12.5 & $2 \cdot 6$ & 12.5 & $2 \cdot 8$ & 09 \\
\hline 0.63 & 0.24 & 62 & 0.23 & 0.585 & 61 & 0.26 & 59 & 0.24 & & 62 & 0.25 & 60 & 0.24 & 507 \\
\hline 1. & 5 & $9 \cdot 8$ & $5 \cdot 8$ & 0 & $51 \cdot 3$ & $5 \cdot 5$ & 49.0 & $7 \cdot 0$ & & 51.1 & 5.4 & 49.3 & $6 \cdot 5$ & 03 \\
\hline $16 \cdot 1$ & 6.5 & 15.5 & 7.7 & 0.366 & $15 \cdot 3$ & 6.5 & $15 \cdot 1$ & $7 \cdot 7$ & 0.660 & $15 \cdot 7$ & 6.5 & $15 \cdot 2$ & 7.6 & 0.307 \\
\hline $12 \cdot 7$ & 4.3 & 13.5 & $5 \cdot 2$ & 0.444 & $10 \cdot 8$ & 3.4 & $10 \cdot 4$ & 4.0 & 0.371 & 11.8 & 4.0 & 11.7 & 4.8 & 0.637 \\
\hline 3.0 & 1.6 & $3 \cdot 2$ & 1.5 & 0.329 & $2 \cdot 8$ & $1 \cdot 7$ & $2 \cdot 8$ & 1.4 & 0.871 & 2.9 & 1.7 & 3.0 & 1.5 & 0.493 \\
\hline
\end{tabular}

TE, total energy (includes energy from alcohol); EAR, estimated average requirement (as set by the Committee on Medical Aspects of Food Policy (COMA)); FE, food energy; $\mathrm{RNI}$, reference nutrient intake (as set by COMA); TFA, trans-fatty acids; CHO, carbohydrate; NMES, non-milk extrinsic sugars; NSP by the Englyst method; 5-a-day, fruit and vegetable '5-a-day' portions.

* Natural logarithm transformation applied to carry out $t$ tests; mean values and standard deviations shown are untransformed values.

† Square root transformation applied to carry out $t$ tests; mean values and standard deviations shown are untransformed values.

‡ Data on fruit and vegetable '5-a-day' portions only available for the 11-18 years age group.

in mean daily energy intakes (as a percentage of EAR) with meal timing, in comparison with findings from adult studies ${ }^{(17,35)}$. In accordance with recent studies of adult populations ${ }^{(12,14)}$, no clear patterns in variation of nutrient intakes with evening meal timings were identified, with only a few, relatively small significant differences found. These comprised an increased percentage intake of proteins among 4-10-year-old boys and decreased percentage intake of carbohydrates among 11-18-year-olds and 11-18-year-old girls when the evening meal was consumed after $v$. before 20.00 hours. Overall, no broad conclusions could be reached on the associations between meal timings and nutrient intakes, except that different evening meal timings do not appear to be linked with variations in overall energy intakes (expressed as a percentage of EAR) for 4-18-year-olds in the NDNS 2008-12 RP core sample.

In common with other studies using self-reporting methods of dietary assessment ${ }^{(36)}$, one of the limitations of this study was under-reporting of food intake. This could be a particular problem with children, who may have difficulties conceptualising portion sizes and accurately recalling intakes ${ }^{(37)}$. However, in the NDNS
RP, doubly labelled water techniques used to validate energy intakes for a sample of survey participants found a lower degree of under-reporting in children than adults. For children aged 4-10 years, energy intakes were $12 \%$ lower than the total energy expenditure (TEE), for children aged 11-15 years energy intakes were $26 \%$ lower and for 16-64-year-olds energy intakes were $34 \%$ lower than the TEE. In this study, the majority of nutrient variables used were expressed as a percentage of food energy, and thus under-reporting should have a limited effect on associations between intakes of these nutrients and meal timing if under-reporting is evenly spread across nutrient types. However, under-reporting of intakes may be particularly high for 'unhealthy' foods and snacks ${ }^{(38,39)}$. Moreover, under-reporting could affect the categorisation of evening meal times, if the level of under-reporting varies with the time of food consumption (e.g. depending on whether parents are present ${ }^{(39)}$ ). The much lower total energy intakes as a percentage of EAR that we found for 11-18-year-old children (72\%), compared with values for 4-10-year-old children who had their food diaries completed by their parents (96\%), may be an indication of different levels of 
under-reporting between the two age groups. We tried to overcome this by splitting the sample into two age groups to reduce complications caused by possible differences in under-reporting levels between those groups.

Relationships between weight status and energy intake after 22.00 hours and before 14.00 hours were not explored in this study in children. There is evidence from cross-sectional studies that breakfast skipping is associated with higher BMI in children $^{(9)}$. It may also affect the timing of the other meals in the day, such as the evening meal. However, a recent study in adults found that there was no within-person difference in evening meal time between days on which breakfast was consumed and days when it was not consumed ${ }^{(40)}$. In addition, the pattern of nutrient intakes and meal timings for children may be different at the weekends compared with weekdays. Owing to oversampling of weekend days in Year 1 of the NDNS 2008-12 RP that has not been completely corrected for in subsequent years, there is a slightly higher proportion of weekend food diary days in the combined 4-Year NDNS 2008-12 RP data set ${ }^{(21)}$. In addition, combining data for weekends and weekdays may produce misleading patterns of associations $^{(17)}$, or obscure significant associations ${ }^{(15)}$.

A limitation of this study is that the power of the analysis to detect statistically significant associations was impaired by the limited numbers of $4-10$-year-olds consuming their evening meal after 20.00 hours ( $n 25,3 \%$ of $4-10$-year-olds). In addition, in common with other observational studies, there is the potential risk of unexplained residual confounding. Logistic regression models were adjusted for income, ethnicity and, where appropriate, sex. An adjustment was not made for age as the sample had already been split into two age groups and it was felt that it would result in over-adjustment. Another important potential confounding variable in the assessment of a link between meal timing and weight status was the physical activity level of the children. Unfortunately, it was not possible to adjust for this variable, as physical activity levels were measured by different methods across the sample age group: by the physical activity monitor (ActiGraph) for 4-15-year-olds (only $52 \%$ provided usable data) ${ }^{(21)}$ and by self-completion questionnaire for older children ${ }^{(25)}$. Short sleep duration was another potential confounding factor ${ }^{(41)}$; however, usable sleep data were unavailable for the majority of children. Other possible confounding variables that have not been controlled for in the logistic regression are dietary constituents (e.g. high-fat diet $v$. low-fat diet) and parental characteristics, for example, education, BMI and employment status. In particular, maternal employment has been shown to be associated with child weight status ${ }^{(42)}$ and may also affect evening meal times. In addition, there may be genetic and epigenetic influences on eating times - for example, a SNP in the CLOCK gene has been found to be associated with delayed breakfast time in adults ${ }^{(43)}$. However, genetic influences may be less important for children than for adults, as their evening meal times may be dictated more by external influences such as parental choice and after-school activities than personal preference.

One of the strengths of this study is that in the analysis of a potential association between evening meal timing and intakes of energy and nutrients, variations due to age and sex have been limited by stratifying the sample by age group and sex and, to the extent possible, by using dietary variables expressed as a percentage of DRV or food energy intakes. Owing to the cross-sectional nature of this study, it can only detect associations between variables and not show causality. In addition, if any associations had been found between late evening meal time and weight status, they could also have been due to reverse causality. Nevertheless, this study does provide valuable additional information in an under-researched area. The data analysed were gathered using 4-d estimated food diaries, which, despite being considered the gold standard for dietary assessment ${ }^{(44)}$, are infrequently used in large national surveys. We used the novel approach of identifying the evening meal time period by comparing the energy intake in each of the several time periods. There is scope for repeating the analysis when data for subsequent years of the NDNS RP become available, which may reveal associations not uncovered in this study due to limited statistical power.

In conclusion, we have found no evidence to suggest that risk of obesity and overweight/obesity in children aged 4-18 years in the UK is associated with evening meal timing or that feeding children their evening meal later is associated with increased energy intake or major differences in dietary patterns. Thus, our results do not support our original hypothesis that children with a later evening meal time have a greater risk of being overweight and/or obese, have higher daily intakes of energy and have poorer quality of diet.

\section{Acknowledgements}

The authors thank everyone involved in the National Diet and Nutrition Survey Rolling Programme (2008-2012), the data from which formed the basis of this study.

This research received no specific grant from any funding agency, commercial or not-for-profit sectors.

J. D. C. formulated the research question, prepared the data for analysis, analysed and interpreted the data and wrote the manuscript, all under the supervision of G. K. P. G. K. P carried out additional analysis of the data. Both the authors approved the final draft before publication.

The authors declare that there are no conflicts of interest.

\section{References}

1. Dehghan M, Akhtar-Danesh N \& Merchant AT (2005) Childhood obesity, prevalence and prevention. Nutr J 4, 24.

2. Johnston JD (2014) Physiological responses to food intake throughout the day. Nutr Res Rev 27, 107-118.

3. Garaulet M \& Gómez-Abellán P (2014) Timing of food intake and obesity: a novel association. Physiol Behav 134, 44-50.

4. Jakubowicz D, Barnea M, Wainstein J, et al. (2013) High caloric intake at breakfast vs. dinner differentially influences weight loss of overweight and obese women. Obesity (Silver Spring) 21, 2504-2512.

5. Salgado-Delgado R, Angeles-Castellanos M, Saderi N, et al. (2010) Food intake during the normal activity phase prevents obesity and circadian desynchrony in a rat model of night work. Endocrinology 151, 1019-1029. 
6. Eckel-Mahan K \& Sassone-Corsi P (2013) Metabolism and the circadian clock converge. Physiol Rev $93,107-135$.

7. Zelinski EL, Deibel SH \& McDonald RJ (2014) The trouble with circadian clock dysfunction: multiple deleterious effects on the brain and body. Neurosci Biobehav Rev 40, 80-101.

8. Oike H, Oishi K \& Kobori M (2014) Nutrients, clock genes, and chrononutrition. Curr Nutr Rep 3, 204-212.

9. Berg C, Lappas G, Wolk A, et al. (2009) Eating patterns and portion size associated with obesity in a Swedish population. Appetite 52, 21-26.

10. Antunes LC, Levandovski R, Dantas G, et al. (2010) Obesity and shift work: chronobiological aspects. Nutr Res Rev 23, 155-168.

11. Gallant R, Lundgren J \& Drapeau V (2012) The night-eating syndrome and obesity. Obes Rev 13, 528-536.

12. Wang JB, Patterson RE, Ang A, et al. (2014) Timing of energy intake during the day is associated with the risk of obesity in adults. J Hum Nutr Diet 27, Suppl. 2, 255-262.

13. Bertéus Forslund H, Lindroos AK, Sjöström L, et al. (2002) Meal patterns and obesity in Swedish women - a simple instrument describing usual meal types, frequency and temporal distribution. Eur J Clin Nutr 56, 740-747.

14. Bo S, Musso G, Beccuti G, et al. (2014) Consuming more of daily caloric intake at dinner predisposes to obesity. A 6-year population-based prospective cohort study. PLOS ONE 9, e108467.

15. Thompson OM, Ballew C, Resnicow K, et al. (2006) Dietary pattern as a predictor of change in BMI z-score among girls. Int J Obes (Lond) 30, 176-182.

16. Eng S, Wagstaff DA \& Kranz S (2009) Eating late in the evening is associated with childhood obesity in some age groups but not in all children: the relationship between time of consumption and body weight status in U.S. children. Int $J$ Behav Nutr Phys Act 6, 27-34.

17. de Castro JM (2004) The time of day of food intake influences overall intake in humans. J Nutr 134, 104-111.

18. Cahill LE, Chiuve SE, Mekary RA, et al. (2013) Prospective study of breakfast eating and incident coronary heart disease in a cohort of male US health professionals. Circulation 128, 337-343.

19. Yannakoulia M, Brussee SE, Drichoutis AC, et al. (2012) Food consumption patterns in mediterranean adolescents: are there differences between overweight and normal-weight adolescents? J Nutr Educ Behav 44, 233-239.

20. NatCen Social Research, MRC Human Nutrition Research \& University College London (2014) National Diet and Nutrition Survey Years 1-4, 2008/09-2011/12. 6th ed. Colchester, Essex: UK Data Archive.

21. Bates B, Lennox A, Prentice A, et al. (2014) National Diet and Nutrition Survey Results from Years 1, 2, 3 and 4 (combined) of the Rolling Programme (2008/2009-2011/2012). London: Public Health England.

22. NatCen Social Research, MRC Human Nutrition Research \& University College London (2014) National Diet and Nutrition Survey Rolling Programme Years 1-4 2008/09-2011/12 User Guide for UK Core Sample Data. Colchester, Essex: UK Data Archive.

23. NatCen Social Research, MRC Human Nutrition Research \& University College London (2014) P2753 National Diet and Nutrition Survey (NDNS) Year 4 Interviewer Project Instructions. Colchester, Essex: UK Data Archive.

24. Cole TJ, Freeman JV \& Preece MA (1995) Body mass index reference curves for the UK, 1990. Arch Dis Child 73, 25-29.

25. Lennox A, Fitt E, Whitton C, et al. (2014) Appendix A to National Diet and Nutrition Survey. Results from Years 1-4 (combined) of the Rolling Programme (2008/2009-2011/12).
Dietary Data Collection and Editing. London: Public Health England.

26. Food Standards Agency (2002) McCance and Widdowson's The Composition of Foods, 6th ed. Cambridge: Royal Society of Chemistry.

27. NHS Choices (2015) Department of Health's 5 a day programme. http://www.nhs.uk/Livewell/5ADAY/Pages/5ADAYhome. aspx (accessed July 2015).

28. Englyst HN, Quigley ME \& Hudson GJ (1994) Determination of dietary fibre as non-starch polysaccharides with gas-liquid chromatographic, high-performance liquid chromatographic or spectrophotometric measurement of constituent sugars. Analyst 119, 1497-1509.

29. Scientific Advisory Committee on Nutrition (2015) Carbohydrates and Health. Norwich: The Stationery Office.

30. NHS Choices (2014) Eight tips for healthy eating. http://www. nhs.uk/Livewell/Goodfood/Pages/eight-tips-healthy-eating.aspx (accessed July 2015).

31. NHS Choices (2015) Fat: the facts. http://www.nhs.uk/Livewell/Goodfood/Pages/Fat.aspx (accessed July 2015).

32. Committee on Medical Aspects of Food Policy (1991) Dietary Reference Values for Food Energy and Nutrients for the United Kingdom. London: The Stationery Office.

33. Feise RJ (2002) Do multiple outcome measures require p-value adjustment? BMC Med Res Methodol 2, 8-11.

34. Tipping S (2014) Appendix B to National Diet and Nutrition Survey Results from Years 1,2,3 and 4 (combined) of the Rolling Programme (2008/09-2011/12). Weighting the NDNS Core Sample. London: Public Health England.

35. Baron KG, Reid KJ, Horn LV, et al. (2013) Contribution of evening macronutrient intake to total caloric intake and body mass index. Appetite 60, 246-251.

36. Thompson FE \& Subar AF (2013) Dietary assessment methodology. In Nutrition in the Prevention and Treatment of Diseases, 3rd ed., pp. 5-46 [M Ferruzzi, AM Coulston and CJ Boushey, editors]. San Diego, CA: Academic Press.

37. Baranowski T \& Domel SB (1994) A cognitive model of children's reporting of food intake. Am J Clin Nutr 59, 212S-217SS.

38. Poppitt SD, Swann D, Black AE, et al. (1998) Assessment of selective under-reporting of food intake by both obese and non-obese women in a metabolic facility. Int $J$ Obes Relat Metab Disord 22, 303-311.

39. Livingstone MBE, Robson PJ \& Wallace JMW (2004) Issues in dietary intake assessment of children and adolescents. $\mathrm{Br} \mathrm{J}$ Nutr 92 , S213.

40. Kant AK \& Graubard BI (2015) Within-person comparison of eating behaviors, time of eating, and dietary intake on days with and without breakfast: NHANES 2005-2010. Am J Clin Nutr 102, 661-670.

41. Chen X, Beydoun MA \& Wang Y (2008) Is sleep duration associated with childhood obesity? A systematic review and meta-analysis. Obesity (Silver Spring) 16, 265-274.

42. Ziol-Guest KM, Dunifon RE \& Kalil A (2013) Parental employment and children's body weight: mothers, others, and mechanisms. Soc Sci Med 95, 52-59.

43. Garaulet M, Sánchez-Moreno C, Smith CE, et al. (2011) Ghrelin, sleep reduction and evening preference: relationships to CLOCK 3111 T/C SNP and weight loss. PLOS ONE $\mathbf{6}$, e17435.

44. Pot GK, Richards M, Prynne CJ, et al. (2014) Development of the Eating Choices Index (ECI): a four-item index to measure healthiness of diet. Public Health Nutr 17, 2660-2666. 